Portland State University

PDXScholar

\title{
Far-Red and Near-Infrared Seminaphthofluorophores for Targeted Pancreatic Cancer Imaging
}

\author{
Lei Wang \\ Portland State University \\ Connor W. Barth \\ Oregon Health \& Science University \\ Martha Sibrian-Vazquez \\ Portland State University, sibrianv@pdx.edu \\ Jorge O. Escodedo \\ Portland State University \\ Mark Lowry \\ Portland State University
}

See next page for additional authors

Follow this and additional works at: https://pdxscholar.library.pdx.edu/chem_fac

Part of the Chemistry Commons

Let us know how access to this document benefits you.

\section{Citation Details}

Wang, L., Barth, C. W., Sibrian-Vazquez, M., Escobedo, J. O., Lowry, M., Muschler, J., ... \& Strongin, R. M. (2017). Far-Red and Near-Infrared Seminaphthofluorophores for Targeted Pancreatic Cancer Imaging. ACS omega, 2(1), 154-163.

This Article is brought to you for free and open access. It has been accepted for inclusion in Chemistry Faculty Publications and Presentations by an authorized administrator of PDXScholar. Please contact us if we can make this document more accessible: pdxscholar@pdx.edu. 


\section{Authors}

Lei Wang, Connor W. Barth, Martha Sibrian-Vazquez, Jorge O. Escodedo, Mark Lowry, John Muschler, Haiyan Li, Summer L. Gibbs, and Robert Strongin 


\section{ACCS

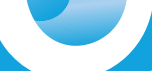 \\ Far-Red and Near-Infrared Seminaphthofluorophores for Targeted Pancreatic Cancer Imaging}

Lei Wang, ${ }^{\dagger}$ Connor W. Barth, ${ }^{\ddagger}$ Martha Sibrian-Vazquez, ${ }^{\dagger}$ Jorge O. Escobedo, ${ }^{\dagger}$ Mark Lowry, ${ }^{\dagger}$ John Muschler, ${ }^{\ddagger}$ Haiyan Li, ${ }^{\ddagger}$ Summer L. Gibbs, ${ }^{\ddagger},, \|$ and Robert M. Strongin ${ }^{*},, \| \oplus$

${ }^{\dagger}$ Department of Chemistry, Portland State University, 1719 SW 10th Avenue, Portland, Oregon 97201, United States

${ }^{\ddagger}$ Biomedical Engineering Department, ${ }^{\S}$ Knight Cancer Institute, "OHSU Center for Spatial Systems Biomedicine, Oregon Health \& Science University, 3181 SW Sam Jackson Park Road, Portland, Oregon 97239, United States

Supporting Information

ABSTRACT: Molecular probes that selectively highlight pancreatic cancer (PC) tissue have the potential to improve pancreatic ductal adenocarcinoma (PDAC) margin assessment through the selective highlighting of individual PC cells. Herein, we report a simple and unique family of systematically modified red and near-infrared fluorescent probes that exhibit a field-effect-derived redshift. Two of thirteen probes distributed to the normal mouse pancreas following systemic administration. One selectively accumulated in genetically modified mouse models of PDAC. The probe exhibited intracellular accumulation and enabled visualization of four levels of the structure, including the whole organ, resected tissue, individual cells, and subcellular organelles. In contrast to the small-molecule probes reported previously, it possesses an inherent affinity toward PDAC cells and thus does not require conjugation to any targeting agent. The fluorescent probe can thus promote new strategies not only for precision image-guided surgery, but also for PC detection, monitoring of therapeutic outcomes, and basic

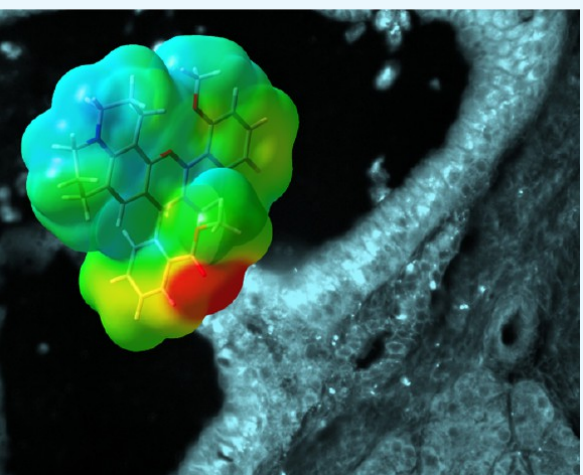
research.

\section{INTRODUCTION}

It was estimated that approximately 53000 people would have been diagnosed with pancreatic cancer (PC) in the United States in 2016 and would have had a postdiagnosis life expectancy of 5-7 months. ${ }^{1}$ PC is projected to become the second leading cause of cancer-related death by $2030 .^{2}$ Pancreatic ductal adenocarcinoma (PDAC) is the most prevalent form of PC. Current screening for PDAC using techniques such as magnetic resonance imaging and computed axial tomography is relatively expensive and ineffective, as over half of all cases are diagnosed after metastasis has occurred, limiting treatment options. Surgical resection is the treatment of choice because chemotherapy and/or radiation therapy alone do not significantly improve life expectancy. ${ }^{3}$ Unfortunately, surgical resection is only possible in $15-20 \%$ of cases. Moreover, to date there has been no intraoperative guidance to differentiate malignant pancreas from normal pancreatic tissues. PC and healthy tissue are currently distinguished through white light visualization and palpation as well as by rapid frozen section (FS) analysis using histopathological pattern recognition through standard hematoxylin and eosin (H\&E) staining while the surgical resection is in progress. ${ }^{5}$

Intraoperative assessment of PDAC margin status during surgery is challenging using current technology. Nearly $75 \%$ of all patients have residual disease from margins not assessed by FS analysis. Limitations of FS analysis include negative assessments due to time constraints in the operating room and microscopic metastases not detected at the time of surgery. ${ }^{6}$ In addition, cellular architecture distortion and tissue artifacts are common issues that occur during FS sample preparation. Slides produced by formalin-fixed paraffinembedded tissue processing would be highly desirable over FS-based H\&E; however, it is well known that the tissue processing time is too lengthy for intraoperative use.

Fluorescence imaging has the potential to improve PDAC detection during surgery via the use of highly tumor-specific molecular probes to facilitate tumor identification. It offers the potential for less subjective, rapid, real-time ex vivo confirmation of negative margin status during surgery. Nearinfrared (NIR) fluorophores have excitation and emission maxima between 650 and $900 \mathrm{~nm}$, where hemoglobin and $\mathrm{H}_{2} \mathrm{O}$ have their lowest absorption coefficients. Moreover, NIR phonons cause minimal photoinduced damage to biological samples and have relatively high tissue penetration depth and signal-to-background ratios (SBRs). Therefore, NIR probes can enhance the overall image quality and collection time. However, to date there are no clinically approved PC-specific fluorescent dyes. Commercially available dyes, including the only FDA-approved in vivo fluorescent contrast agents, indocyanine green, methylene blue (MB), and fluorescein,

Received: November 17, 2016

Accepted: December 27, 2016

Published: January 20, 2017 
exhibit nonspecific fluorescence and largely act as blood pool agents.

\section{RESULTS AND DISCUSSION}

One of the main challenges in PDAC therapy is drug delivery and is largely attributed to the hypovascular and fibrotic tumor microenvironment. ${ }^{7}$ Thus, to attain desirable PDAC-selective accumulation and SBR, we have synthesized a focused library of systematically modified 1-substituted benzo[c]xanthene fluorophores (Figure 1) to begin to define factors modulating tissue

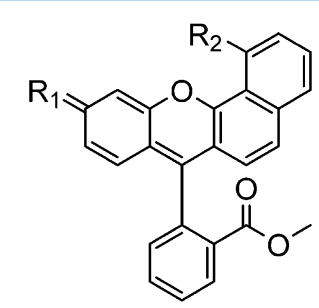

$1 R_{1}=0$

$\mathrm{R}_{2}=\mathrm{OH}$

$2 \mathrm{R}_{1}=\mathrm{O}$

$3 \mathrm{R}_{1}={ }^{+} \mathrm{NH}_{2}$

$\mathrm{R}_{2}=\mathrm{OCH}_{3}$

$\mathrm{R}_{2}=\mathrm{OH}$

$4 \mathrm{R}_{1}={ }^{+} \mathrm{NH}_{2}$

$\mathrm{R}_{2}=\mathrm{OCH}_{3}$

$5 \mathrm{R}_{1}={ }^{+} \mathrm{N}\left(\mathrm{CH}_{3}\right)_{2} \quad \mathrm{R}_{2}=\mathrm{OH}$

$6 \quad \mathrm{R}_{1}={ }^{+} \mathrm{N}\left(\mathrm{CH}_{3}\right)_{2} \quad \mathrm{R}_{2}=\mathrm{OCH}_{3}$

$7 \quad \mathrm{R}_{1}=0$

$8 \quad R_{1}=0$

$9 \mathrm{R}_{1}={ }^{+} \mathrm{NH}_{2}$

$\mathrm{R}_{2}=\mathrm{NH}_{2}$

$10 \mathrm{R}_{1}={ }^{+} \mathrm{N}\left(\mathrm{CH}_{3}\right)_{2}$

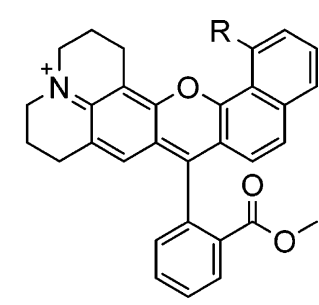

$11 \mathrm{R}=\mathrm{OH}$

$12 \mathrm{R}=\mathrm{OCH}_{3}$

$13 \mathrm{R}=\mathrm{NH}_{2}$
Figure 1. 1-Substituted benzo $[c]$ xanthene library.

biodistribution, ${ }^{8}$ such as probe size, lipophilicity, solubility, and ionization state. To minimize the effects of autofluorescence, these compounds were designed to exhibit significant bathochromic shifts compared to traditional long-wavelength 3substituted benzo[c]xanthenes via the formal repositioning of polar groups. $^{9-12}$

Compounds 1-13 (Figure 1) were designed taking into account the uptake and related "drug-like" properties that can be used as quantitative descriptors for predicting and optimizing biodistribution and tissue targeting. ${ }^{13}$ The predicted absorption spectra and physicochemical properties of 1-13 are shown in Figures S1-S3 (Supporting Information (SI)). Compounds 1-13 exhibit maximum absorption peaks between 400 and $650 \mathrm{~nm}$ and are within the requirements to be considered for tissue targeting according to the Lipinski ${ }^{14}$ and Veber $^{15}$ rules. $\log D$ values ranged from 0.5 to 5 (Lipinski rule: $<5)$, molecular weights were between 400 and $500 \mathrm{~g} / \mathrm{mol}$ (Lipinski rule: $<500 \mathrm{~g} / \mathrm{mol}$ ), $0-4$ hydrogen bond donors (Lipinski rule: $<5$ ) and $4-5$ hydrogen bond acceptors (Lipinski rule: $<10)$ were present, and polar surface areas ranged between 48 and $87 \AA^{2}$ (Veber rule: $<140 \AA^{2}$ ). Experimental details for the synthesis of each compound are provided in the SI.

The spectral properties of this series of probes (1-13), based on seminaphthofluorescein, seminaphthorhodafluor, and seminaphthorhodamine scaffolds, were screened for $\mathrm{pH}$ and solvent dependence (Figure 2, Table 1, and Figures S4-S9). Absorption and fluorescence spectra of compounds containing ionizable hydroxyl groups (seminaphthofluorescein $\mathbf{1}$ and seminaphthorhodafluors 3, 5, and 11) exhibited $\mathrm{pH}$ dependence over the physiological range (Figures S4 and S5) and solvatochromic effects (Figure S5). In aqueous solution, the hydroxyl forms of $\mathbf{1}, \mathbf{3}, \mathbf{5}$, and $\mathbf{1 1}$ were red emitting, whereas their conjugate bases exhibited NIR fluorescence. Solvent dependence is at least partially attributable to differences in the equilibria between tautomeric forms of the compounds in the various solvents tested. Solvent and $\mathrm{pH}$ sensitivity were addressed via derivatization. Methoxy-functionalized analogues $(2,4,6$, and 12) displayed relatively bright red fluorescence and were independent of variations in $\mathrm{pH}$ (Figures S6 and S7) and solvent composition (Figure S7). Replacing the hydroxyl group with an amine generated a series of NIR-emitting seminaphthorhodamines $(\mathbf{9}, \mathbf{1 0}$, and $\mathbf{1 3})$. The spectral properties of 9, 10, and 13 were $\mathrm{pH}$ independent and only modestly dependent on solvent composition (Figure S8). Transposition of the hydroxyl and amine functionalities in seminathorhodafluors 3 and 5 generated compounds 7 and 8. This lowered their $\mathrm{p} K_{\mathrm{a}}$ values, resulting in spectral properties that were not $\mathrm{pH}$ dependent in the physiological range.

Compounds 2, 12, and 13 are representative of the three classes of benzo $[c]$ xanthenes designed in this study and were chosen as candidates for initial in vivo and ex vivo screening for pancreas and PDAC targeting based on the following considerations. First, their predicted physiochemical properties (Figures $S 1-S 3$ ) cover a relatively broad range of $\log D$ values, enabling evaluation of the influence of lipophilicity on targeting. Second, each exhibits desirable $\mathrm{pH}$ independence. Third, their spectral properties (Figures S6-S8) show that they have the highest quantum yield and brightness within each of the three classes of benzo[ $[c]$ xanthenes. The predicted physicochemical properties of 2, 12, and 13 are shown in Figure 3, allowing correlation between the in vitro and in vivo targeted localization and the molecular characteristics of the synthesized fluorophores. In vitro cell viability (Figure S10A) and timedependent fluorophore uptake (Figure S10B) were assessed in the presence of compounds 2, 12, and 13 in Capan-1 cells (a representative PDAC cell line). The cytotoxicity studies demonstrated that compound 2 was the least toxic $\left(\mathrm{IC}_{50}\right.$ $30.08 \mu \mathrm{M})$, followed by compounds $13\left(\mathrm{IC}_{50} 26.08 \mu \mathrm{M}\right)$ and $12\left(\mathrm{IC}_{50} 17.79 \mu \mathrm{M}\right)$. Each fluorophore exhibited similar kinetics, demonstrating uptake within $30 \mathrm{~min}$ of fluorophore application. Compound $\mathbf{1 3}$ exhibited the greatest uptake and $\mathbf{2}$ the lowest during this period.

The subcellular localization of $\mathbf{2 , 1 2}$, and 13 was investigated in Capan-1 cells after $1 \mathrm{~h}$ incubation. Organelle-specific fluorescent probes were used to assess the site-specific uptake of each fluorophore. The preferential intracellular localization of compound 2 (Figure S10C) was within vesicular structures that may embody lipid droplets, endosomes, or other membrane-based vesicles. In contrast to 2, compounds 12 (Figure 4) and 13 (Figure S10E) demonstrated more homogeneous distribution across cells with extensive accumulation in the mitochondria (Mito) as well as limited accumulation in the nucleus and endoplasmic reticulum (ER). 12 and 13 are cationic, and they distribute electrophoretically in the mitochondrial matrix in response to the electric potential across the mitochondrial membrane. ${ }^{16}$

The initial biodistribution profile screening of 2,12 , and 13 was carried out in healthy CD-1 mice and compared to that of $\mathrm{MB}$ to assess their pancreas specificity (Figure 5). Compound 12 exhibited the highest and most persistent fluorescence SBR in the pancreas as compared to that in the surrounding organs at the $4 \mathrm{~h}$ time point. It had a 4-fold higher uptake in normal pancreas tissue as compared to that of previously studied $\mathrm{MB}$ 


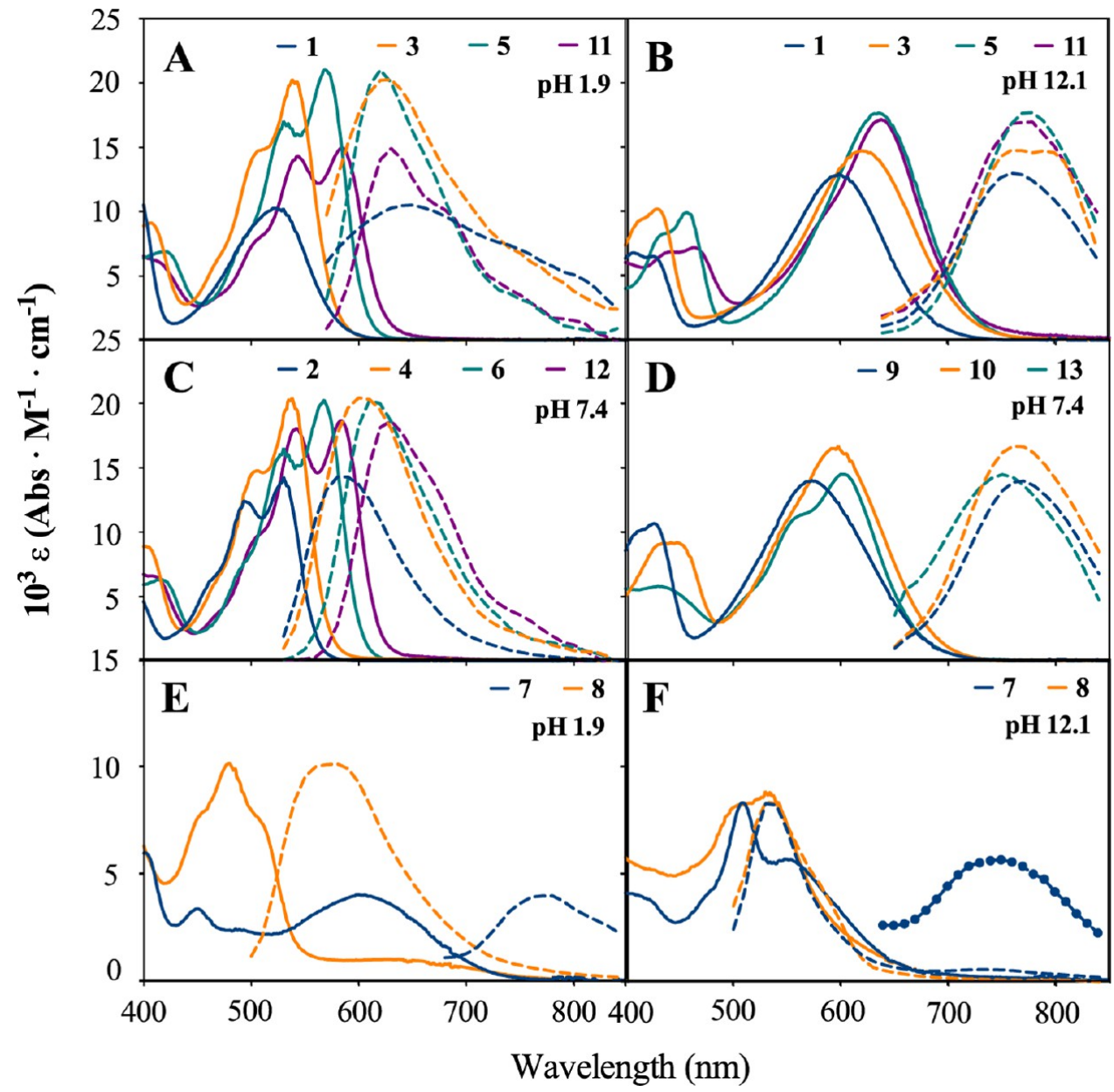

Figure 2. Spectral properties of compounds 1-13 at various $\mathrm{pH}$ values. (A) Absorption spectra (solid lines) and normalized fluorescence emission spectra (dash lines) of $\mathrm{pH}$-dependent seminaphthofluorescein and seminaphthorhodafluors $(\mathbf{1}, \mathbf{3}, \mathbf{5}$, and 11) in acidic solution ( $\mathrm{pH} 1.9, \mathrm{HCl}) .(\mathrm{B})$ Conjugate bases of $\mathbf{1}, \mathbf{3}, \mathbf{5}$, and 11 in basic solution $(\mathrm{pH} 12.1, \mathrm{NaOH}) .(\mathrm{C}) \mathrm{pH}$-independent seminaphthofluorescein and seminaphthorhodafluors $(\mathbf{2}, \mathbf{4}, \mathbf{6}$, and 12) in $\mathrm{pH} 7.4$ buffer. (D) $\mathrm{pH}$-independent seminaphthorhodamines $(\mathbf{9}, \mathbf{1 0}$, and 13) in $\mathrm{pH} 7.4$ buffer. (E) Conjugate acids of transposed seminaphthorhodafluors (7 and 8) in acidic solution ( $\mathrm{pH} \mathrm{1.9,} \mathrm{HCl}) .(\mathrm{F}) 7$ and 8 in basic solution $(\mathrm{pH} \mathrm{12.1,} \mathrm{NaOH})$. Fluorophore concentrations range from 10 to $15 \mu \mathrm{M}$. Aqueous solutions contain $10 \% \mathrm{DMSO}$ and $12.5 \mathrm{mM} \mathrm{HCl}, \mathrm{NaOH}$ or $\mathrm{pH} 7.4$ buffer. Red-emitting fluorophores were excited at 480 or $510 \mathrm{~nm}$, and NIR-emitting fluorophores were excited at $630 \mathrm{~nm}$. Emission spectra are normalized to their corresponding absorption peaks. Excitation Emission Matrices (EEMs) are provided in the SI.

$(\log D=-0.62) . \mathrm{MB}$ extravasated to some degree but demonstrated poor penetration into normal pancreas tissue (Figure S11). The low in vivo efficacy of $\mathrm{MB}$ could be attributed to its relatively low lipophilicity and high water solubility, as it is preferentially and rapidly cleared through the renal system after systemic administration. MB's low tissue fluorescence, rapid clearance rate, and reduced bioavailability limited its pancreas tissue selectivity and thus its potential for image-guided surgery applications. From the study herein, higher $\log D$ value compounds $\mathbf{2}$ and $\mathbf{1 2}$ exhibited improved pancreas specificity, whereas $\mathbf{1 3}$ and $\mathrm{MB}$ had relatively lower $\log D$ values and diminished pancreas accumulation, which correlates well with previous studies. ${ }^{13,17}$

Genetically engineered mouse models of PDAC tumors that recapitulate the clinical, pathological, and genomic features of human PDAC ${ }^{18,19}$ were used to assess the specificity of the designed fluorophores for PDAC accumulation both in vivo and ex vivo. Compound 12, which afforded the highest pancreas tissue uptake in healthy mice, was chosen for further study in the genetically modified PDAC tumor-bearing mouse model. Ex vivo staining of pancreas tissue derived from healthy and PDAC mice showed that their characteristic features were highlighted by 12 (Figure 6A). The healthy mouse pancreas tissue showed uptake of $\mathbf{1 2}$ in its abundant acinar cell population. In contrast, in the cancerous tissue, $\mathbf{1 2}$ localized in the PDAC-associated ductal epithelial cells, enabling them to be observed via an increased fluorescence signal that was visually brighter compared to that of the acinar cells in the healthy tissue. Thus, 12 enabled ex vivo staining to distinguish the features of healthy and PDAC tissue ex vivo (Figure 6A).

Compound 12 was systemically administered to $n=5$ genetically modified PDAC mice. Pancreas-specific fluorescence was monitored over a $1.5 \mathrm{~h}$ period. Significantly more fluorescence was seen in compound 12-injected PDAC-bearing animals compared to that in uninjected control PDAC-bearing animals (Figure 6B,C). After euthanasia, the pancreas was assessed microscopically for PDAC-specific fluorophore accumulation. Representative intraoperative fluorescence images over time as well as the in vivo organ biodistribution kinetics of compound $\mathbf{1 2}$ are shown in Figure S12.

Representative serially sectioned tissues stained with pancytokeratin to assess PDAC specificity of compound 12 
Table 1. Tabulated Spectral Properties of Compounds 1-13 at Various $\mathrm{pH}$ Values ${ }^{a}$

$\begin{array}{cclccc}\text { compound } & \begin{array}{c}\lambda_{\max } \text { abs, nm } \\ \left(\varepsilon, \mathrm{M}^{-1} \mathrm{~cm}^{-1}\right)\end{array} & \begin{array}{c}\lambda_{\max } \text { em, nm } \\ (\varphi, \%)\end{array} & \begin{array}{c}\text { Stokes } \\ \text { shift } \\ (\mathrm{nm})\end{array} & \text { brightness } & \mathrm{p} K_{\mathrm{a}} \\ \mathbf{1} & 530(12167) & 600(1.17) & 70 & 142 & 7.72 \\ 2 & 530(15610) & 580(46.49) & 50 & 7257 & \\ 3 & 542(19787) & 604(1.14) & 62 & 226 & 6.67 \\ 4 & 538(21742) & 596(34.42) & 58 & 7484 & \\ 5 & 567(20399) & 614(4.09) & 47 & 834 & 6.82 \\ 6 & 568(22470) & 606(9.32) & 38 & 2094 & \\ 7 & 509(8300) & 530 & 21 & & \\ 7 & 549(5664) & 750 & 201 & & \\ \mathbf{8} & 530(8834) & 530 & 21 & & \\ 9 & 576(13872) & 760(0.18) & 184 & 25 & \\ 10 & 598(17066) & 770(0.20) & 172 & 34 & \\ 11 & 585(15134) & 624(15.3) & 39 & 2314 & 7.84 \\ 12 & 582(17764) & 622(11.38) & 40 & 2022 & \\ 13 & 601(12808) & 740(0.66) & 139 & 85 & \end{array}$

${ }^{a}$ Fluorophore concentrations range from 10 to $15 \mu \mathrm{M}$. Aqueous solutions contain $10 \%$ DMSO and $12.5 \mathrm{mM} \mathrm{HCl}, \mathrm{NaOH}$ or $\mathrm{pH} 7.4$ phosphate buffer. Tabulated spectral properties of conjugate bases of $1,3,5$, and 11 , as well as conjugate acids of 7 and 8 are provided in the SI.

confirmed that accumulation of compound $\mathbf{1 2}$ in the PDAC tumor tissue was significantly higher than that in the surrounding tissues and that compound $\mathbf{1 2}$ showed specificity for the malignant cells (Figure 7). H\&E staining of the PDAC specimens revealed that uptake of $\mathbf{1 2}$ occurred in ductal tissue epithelial cells, similar to the ex vivo staining pattern (Figures $6 \mathrm{~A}$ and 7). This is consistent with the fact that pancreatic ductal epithelial cells give rise to PDAC. ${ }^{20}$ Furthermore, the accumulation of 12 in PDAC mouse acinar cells (Figure 7D) also demonstrated colocalization with the pan-cytokeratin immunofluorescence staining. This supports studies that have shown that genetic mutations of acinar cells are associated with precancerous pancreatic intraepithelial neoplasia that progresses to PDAC over time. ${ }^{21,22}$

\section{CONCLUSIONS}

In summary, the synthesis of a focused probe library with predictable physicochemical properties afforded a simple molecular probe (12), enabling the imaging of PDAC in a genetically engineered mouse model both in vivo and ex vivo, providing the opportunity for dual clinical utility. Compound 12 offers highly attractive characteristics, such as high contrast, tumor specificity, and adaptation to clinical and intraoperative workflows. Conjugation to a biological targeting agent was not required for PDAC tumor specificity. Compound 12 functioned at the level of the whole organ, enabling visualization of a cancerous pancreas with excellent SBR. It targeted PDAC tissue and cells as evidenced by comparison with $H \& E$ staining and the immunohistochemistry pancytokeratin assay, and it allowed for ready distinction between individual cell morphologies. At the subcellular level, it demonstrated accumulation in the mitochondria. Compound 12 is highly tumor specific, enabling the imaging of PDAC at four different levels of structure in a genetically engineered mouse model. It thus possesses desirable properties for promoting enhanced PC detection, therapeutic monitoring, and image-guided surgery.

\section{METHODS}

Prediction of Physicochemical Properties and Molecular Modeling. Physicochemical partition coefficient $(\log D)$ values at $\mathrm{pH} 7.4$ were calculated using Marvin and JChem calculator plugins (ChemAxon, Budapest, Hungary). Molecular
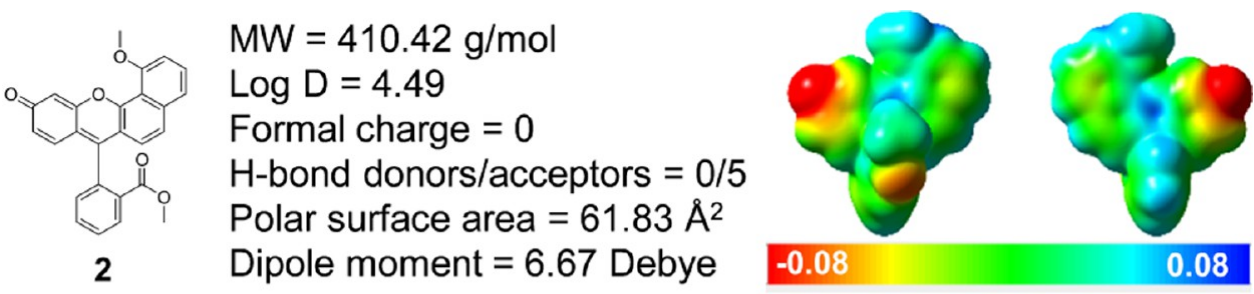

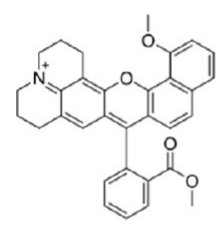

12

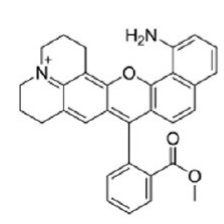

13

$$
\begin{aligned}
& \mathrm{MW}=490.57 \mathrm{~g} / \mathrm{mol} \\
& \text { Log } \mathrm{D}=1.91 \\
& \text { Formal charge }=+1 \\
& \text { H-bond donors } / \text { acceptors }=0 / 4 \\
& \text { Polar surface area }=47.77 \AA^{2} \\
& \text { Dipole moment }=6.52 \text { Debye }
\end{aligned}
$$

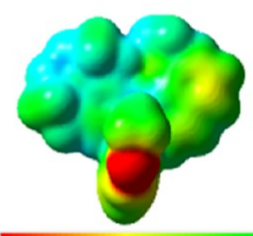

0.05

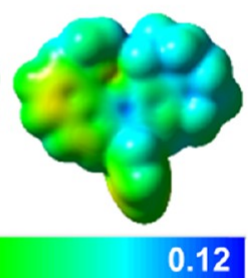

$$
\begin{aligned}
& M W=475.56 \mathrm{~g} / \mathrm{mol} \\
& \text { Log } D=1.24 \\
& \text { Formal charge }=+1 \\
& \text { H-bond donors } / \text { acceptors }=2 / 4 \\
& \text { Polar surface area }=64.56 \AA^{2} \\
& \text { Dipole moment }=6.78 \text { Debye }
\end{aligned}
$$

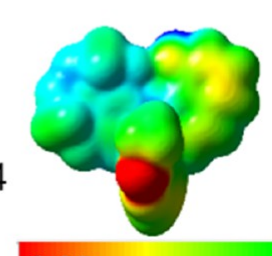

0.05

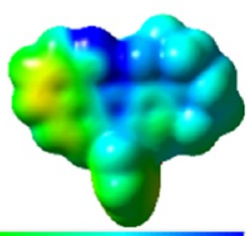

0.12

Figure 3. Structures and summary of calculated physicochemical properties of 2, 12, and 13. Color-mapped surfaces show the molecular electrostatic potential (blue is positive, green is neutral, and red is negative). 

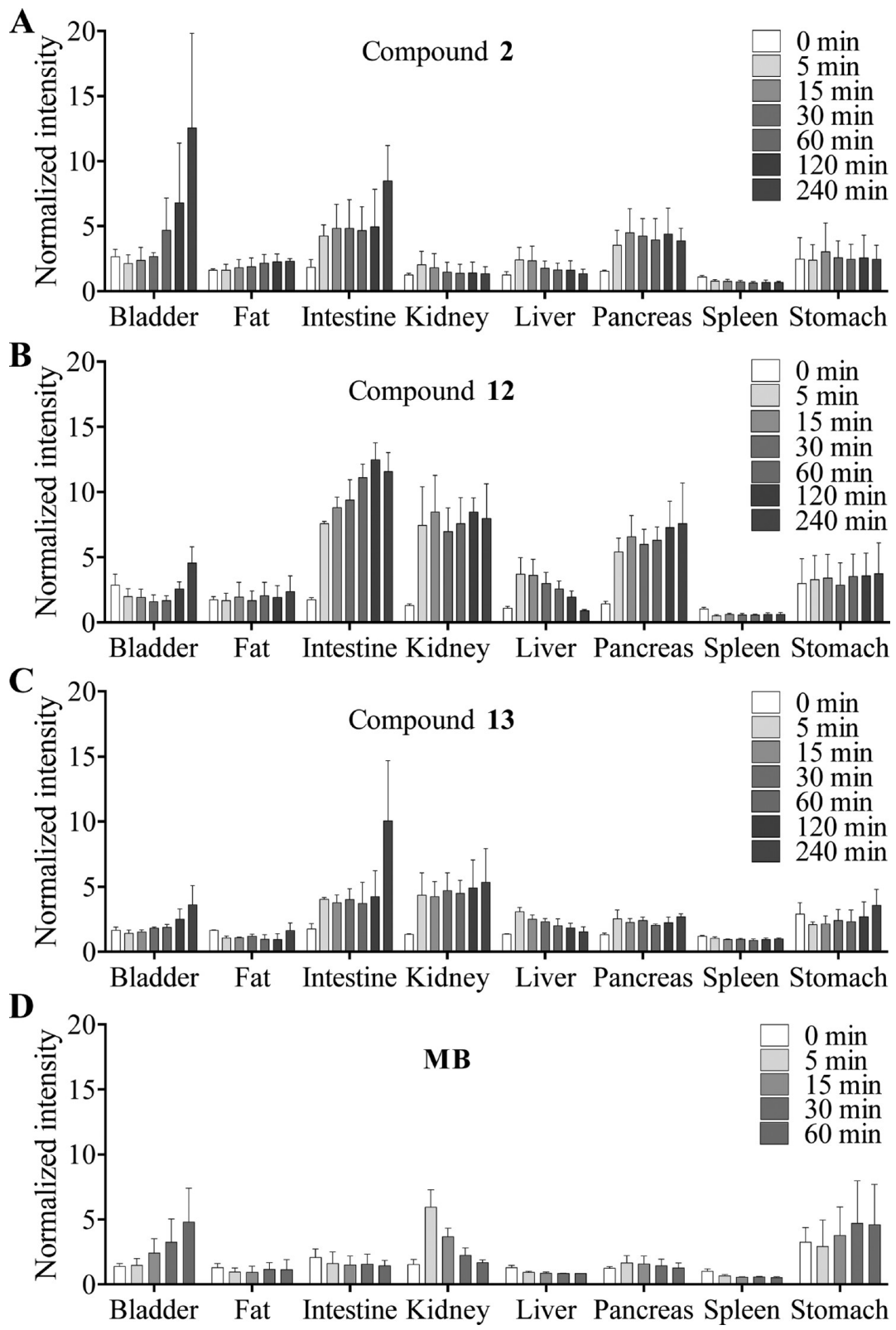

Figure 4. I Subcellular colocalization of compound 12 in Capan-1 cells. Images of subcellular organelles stained with commercial fluorescent trackers (top row) are labeled 4'-6-diamidino-2-phenylindole (DAPI) (blue), ER (green), or Mito (green); bottom row contains merged view of compound 12 with fluorescent organelle trackers.

orbital, UV-vis spectra, and electrostatic map calculations were performed using density functional theory modeling on gasphase B3LYP/6-31G optimized geometries using Gaussian $09 .^{23}$

Synthesis of Fluorescent Probes. Seminaphthofluorescein, seminaphthorhodafluors, and seminaphthorhodamines (Figure 1) were synthesized in two to three steps. The initial step involved the condensation of hydroxybenzophenones with the corresponding naphthols in a mixture of $\mathrm{CH}_{3} \mathrm{SO}_{3} \mathrm{H} / \mathrm{TFA}$ $1: 1$ at $80{ }^{\circ} \mathrm{C}$ for $16-24 \mathrm{~h}$ to produce the lactones or carboxylates. Subsequent Fisher esterification to produce the methyl ester derivatives was carried out in $\mathrm{MeOH}$ catalyzed by either $\mathrm{H}_{2} \mathrm{SO}_{4}$ or $\mathrm{HCl}$. Further alkylation was attained by treatment of either the carboxylate or methyl ester intermediate with methyl iodide in the presence of $\mathrm{K}_{2} \mathrm{CO}_{3}$ in dimethylformamide to produce the corresponding methyl ethers. The required starting materials, 2-(2,4-dihydroxybenzoyl)benzoic acid, 2-(4-amino-2-hydroxybenzoyl)benzoic acid, 2-(8-hydroxy1,2,3,5,6,7-hexahydropyrido[3,2,1-ij] quinoline-9-carbonyl)benzoic acid, and 1,8-naphthalene derivatives, were synthesized according to described or modified literature protocols. In general, overall good yields were obtained for most of the fluorophores included in this series with the exception of the condensation products between 2-(2,4- dihydroxybenzoyl)benzoic acid and 8-amino naphthol derivatives 7 and 8 , where the major isolated product corresponded to fluorescein. All compounds were isolated by flash column chromatography or preparative thin-layer chromatography and characterized by NMR and high-resolution electrospray ionization mass spectrometry.

UV-Vis Absorption and Fluorescence Spectroscopy. UV-vis spectra were collected using a Cary $50 \mathrm{UV}-$ vis spectrophotometer at room temperature (rt) using a reducedvolume $1 \mathrm{~cm}$ quartz cuvette. Fluorescence spectra were 

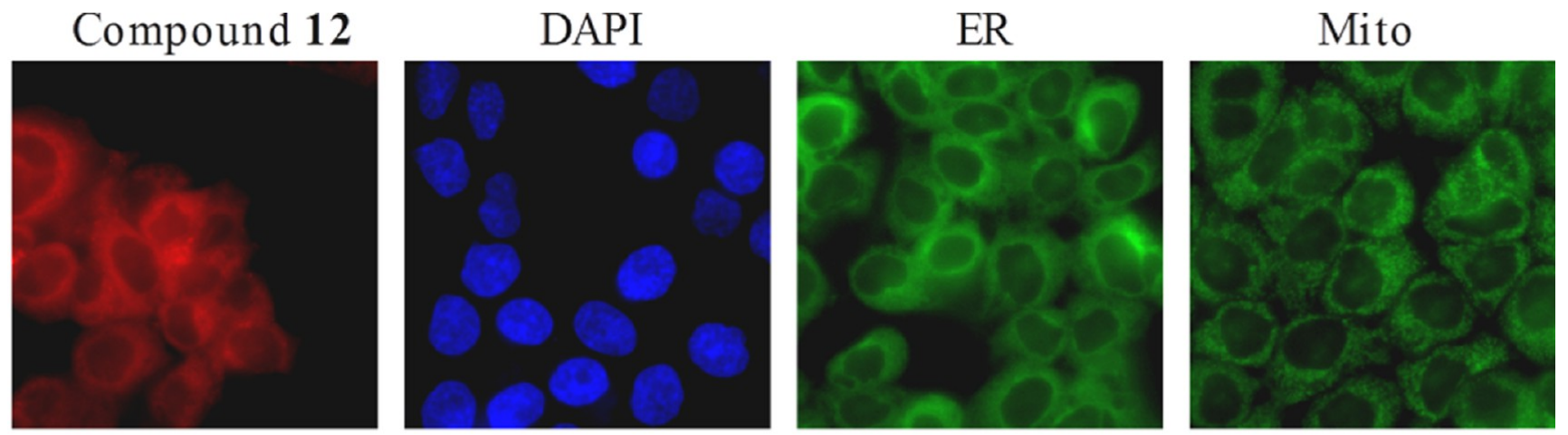

Merge

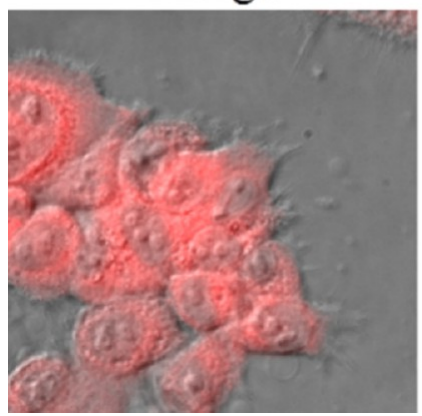

$12+$ DAPI

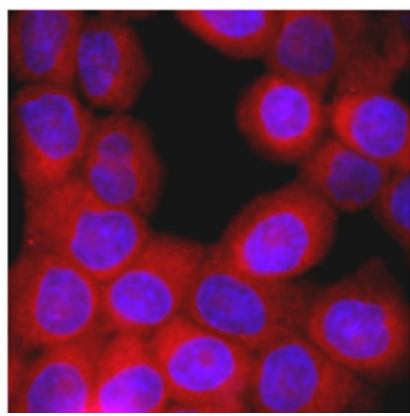

$12+\mathrm{ER}+\mathrm{DAPI}$

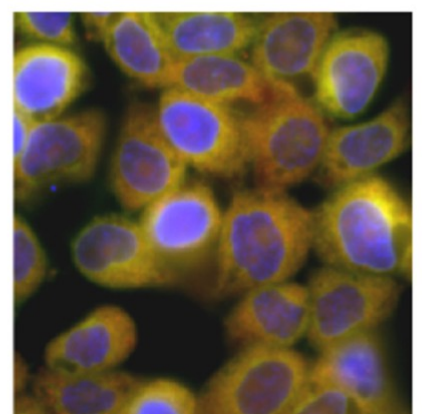

$12+$ Mito +DAPI

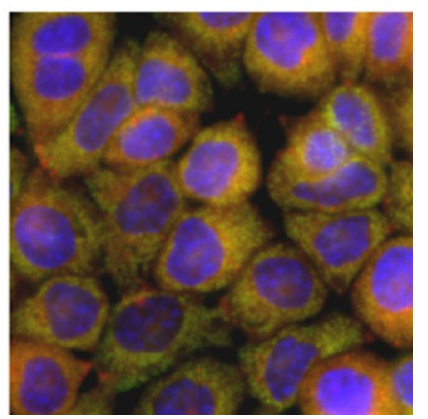

Figure 5. In vivo organ biodistribution kinetics of synthesized compounds vs MB-normalized fluorescence intensity. Mean organ fluorescence intensity following systemic administration of (A) compound 2, (B) compound 12, (C) compound 13, or (D) MB.

collected on a Cary Eclipse fluorescence spectrophotometer (Agilent Technologies). All absorption spectra were reference corrected. Fluorescence spectra were corrected for the wavelength-dependent response of the R928 photomultiplier tube using a manufacturer-generated correction file. Quantum yields were reported as the average of multiple measurements using multiple references. EEMs were collected over various spectral regions, using 5 or $10 \mathrm{~nm}$ step sizes for emission and excitation. The band pass for excitation and emission was 5-10 $\mathrm{nm}$.

Cell Culture. The human PDAC cell line Capan-1 was obtained from Dr. Rosalie Sears's laboratory at Oregon Health and Science University (OHSU) and was maintained in RPMI medium (Gibco) in a humid atmosphere at $37{ }^{\circ} \mathrm{C}$ with $5 \%$ $\mathrm{CO}_{2}$. All media were supplemented with $10 \%(\mathrm{v} / \mathrm{v})$ fetal bovine serum (FBS) and $1 \%(\mathrm{v} / \mathrm{v})$ penicillin/streptomycin. Cell viability was determined by Cell Titer-Blue assay. Monolayers of $10^{4}$ Capan- 1 cells were seeded in triplicate in 96-well plates and incubated with decreasing concentration from $100 \mu \mathrm{M}$ of each compound in growth media containing 10\% FBS. After 24 h incubation time, $20 \mu \mathrm{L}$ of Cell Titer-Blue reagent was added into each well and culture cells were incubated for additional 2 h. Fluorescence intensity in each well was recorded at 560/590 nm using a SpectraMax M5 Microplate Reader. The halfmaximal inhibitory concentrations $\left(\mathrm{IC}_{50}\right)$ of 2,12 , and 13 were determined by interpolating values in the graph (\% cell viability vs fluorophore concentration). For the comparison of cellular uptake rates in Capan-1 cells, the absorbance of the media was measured as background, and the absorbance of the supernatant was obtained to determine the cellular uptake, using the absorbance of $10 \mu \mathrm{M}$ fluorophore in cell-free media as the standard reference.
In Vitro Live Cell Imaging. Monolayers of $10_{4}$ Capan- 1 cells were seeded in triplicate in eight-well plates and incubated for $24 \mathrm{~h}$ in growth mediun containing 10\% FBS and were allowed to attach. For subcellular colocalization experiments, the medium was extracted and cells were washed with phosphate-buffered saline (PBS), and phenol red-free growth medium was added to each well. Organelle trackers were added to each well, and incubated with the fluorophore of interest (final concentration $0.5 \mu \mathrm{M}$ ) for $1 \mathrm{~h}$. Cells were washed with PBS and fixed with $2 \%$ paraformaldehyde (PFA). Fluorescence microscopy was carried out using a Zeiss inverted microscope with an Axioscan fluorescence camera for imaging. The final concentrations of organelle trackers used were as follows: DAPI $0.5 \mu \mathrm{M}$, Mito-tracker green $0.5 \mu \mathrm{M}$, and ER-tracker green 1 $\mu \mathrm{M}$.

Animals. Approval for the use of all animals in this study was obtained from the Institutional Animal Care and Use Committee (IACUC) at OHSU. Male CD-1 mice weighing 22-24 g were purchased from Charles River Laboratories (Wilmington, MA). Genetically engineered mouse models of PDAC based on the targeted expression of an oncogenic KRAS mutation (KRASG12D) in the mouse pancreas were used to model the human disease. Mice expressing the KRAS mutation alone, termed "KC mice", develop the full range of intraductal neoplastic lesions (PanINs) that are histologically indistinguishable from human PanINs. The mice develop PanINs with 100\% penetrance, but these lesions do not progress to metastatic disease. ${ }^{19,24}$ A modification of the KC mouse that was developed in the laboratory of Dr. Rosalie Sears (Department of Molecular \& Medical Genetics, Oregon Health and Science University) was used to more closely model human PDAC. This mouse model, termed "KMC mice", included overexpression of the wild-type Myc oncogene, ${ }^{25,26}$ similar to their 
A
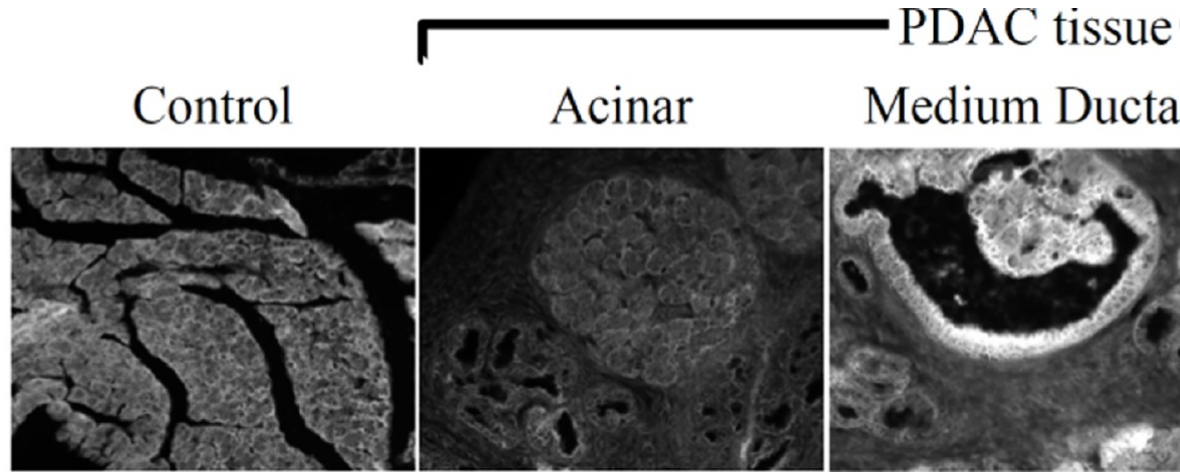
Medium Ductal Large Ductal
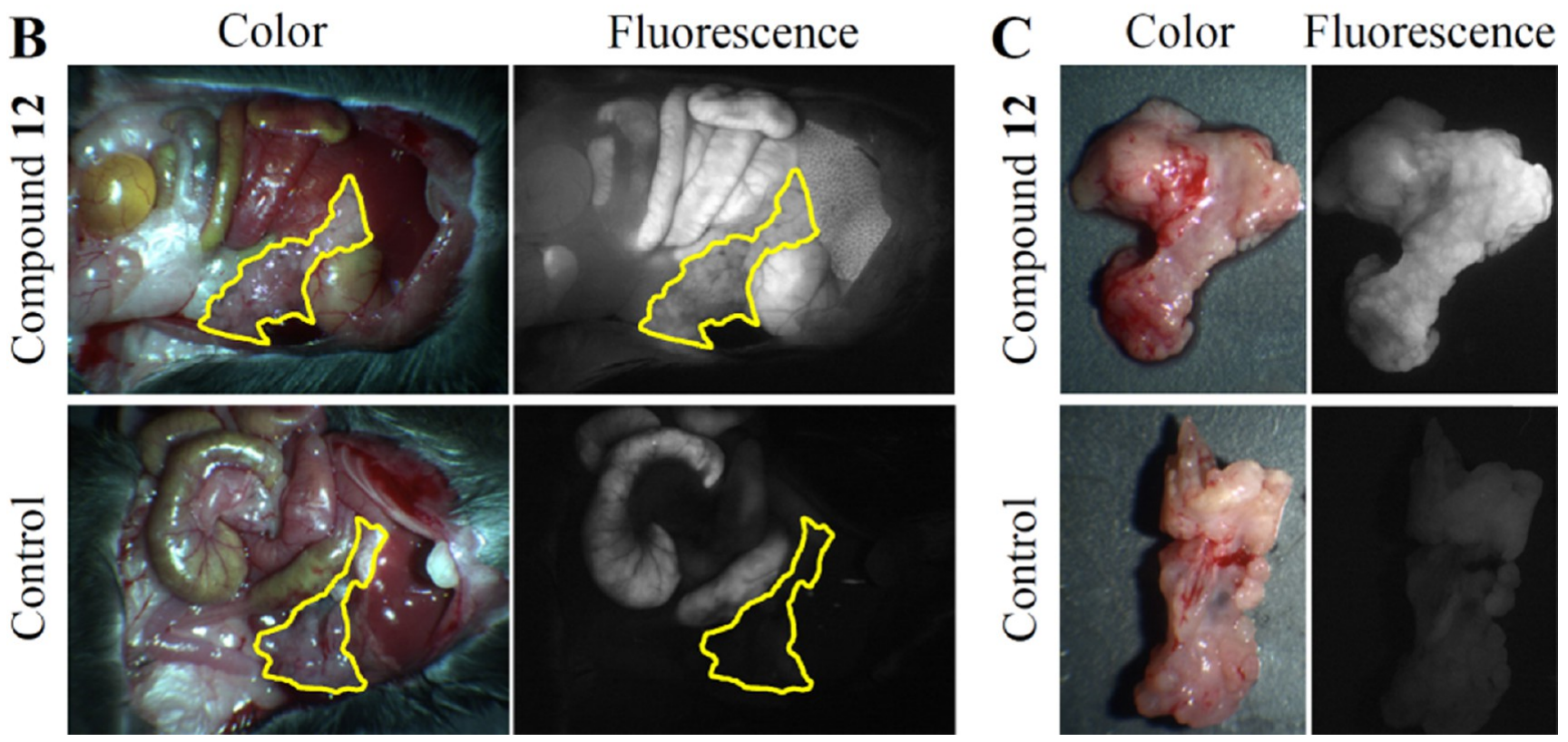

Figure 6. Ex vivo microscopy images of control and PDAC tissue slides stained with compound $\mathbf{1 2}$ and real-time intraoperative fluorescence imaging of PDAC tumor-bearing mice injected with compound 12. (A) Microscopy images of compound 12 stained pancreas tissue. (B) The location of the pancreas in the peritoneal cavity is shown outlined in yellow, with (top) and without (bottom) compound 12 administration. (C) Macroscopic images of resected pancreas tissue from PDAC tumor-bearing mice ex vivo either following systemic administration of compound 12 (top) or from an uninjected PDAC tumor-bearing mouse (bottom) confirming the lack of pancreas fluorescence without 12.

previously published breast cancer mouse models. ${ }^{27}$ This PC mouse model developed PanIN lesions by 10 weeks of age and rapidly progressed to $\mathrm{PDAC}$, including metastatic disease, more closely representing the human disease (Sears Lab OHSU, unpublished data). Both $\mathrm{KC}$ and $\mathrm{KMC}$ mice were used to assess compound $\mathbf{1 2}$ accumulation in PDAC. All animals were placed on 5V75 chlorophyll-free diet from TestDiet (St. Louis, MO) 1 week before any imaging studies. Before surgery, mice were anaesthetized with $100 \mathrm{mg} / \mathrm{kg}$ ketamine and $10 \mathrm{mg} / \mathrm{kg}$ xylazine (Patterson Veterinary, Devens, MA). The peritoneal cavity was surgically exposed by removal of the overlying skin and muscle tissue to image fluorophore biodistribution following intravenous injection.

Intraoperative Fluorescence Imaging System. In vivo murine biodistribution images and macroscopic images of resected tissues were acquired using a custom-built small animal imaging system capable of real-time color and fluorescence imaging. The imaging system consists of a QImaging EXi Blue monochrome camera (Surrey, British Columbia, CA) for fluorescence detection with a removable Bayer filter for collecting co-registered color and fluorescence images. A PhotoFluor II light source ( 89 North, Burlington, VT) was focused onto the surgical field through a liquid light guide and used unfiltered for white light illumination. For fluorescence detection, the light source was filtered using a $545 \pm 12.5,620$ \pm 30 , or $650 \pm 22.5 \mathrm{~nm}$ bandpass excitation filter for compounds 2 and 12, compound 13, and MB fluorescence excitation, respectively. The resultant fluorescence was collected using a $605 \pm 35,700 \pm 37.5$, or $720 \pm 30 \mathrm{~nm}$ bandpass emission filter for compounds 2 and 12, compound 13, and $\mathrm{MB}$ image collection, respectively. All filters were obtained from Chroma technology (Bellows Falls, VT). Camera exposure times ranged from 50 to $200 \mathrm{~ms}$ for fluorescence image collection. All images collected for comparison between treatment groups were acquired with the same exposure time and are displayed under equal normalized brightness and contrast levels where indicated.

Systemic Administration of Fluorescent Compounds. For initial in vivo testing and biodistribution studies, $100 \mathrm{nmol}$ of compounds 2, 12, and 13 were injected systemically. Fluorophores were diluted in PBS. For comparison with previous studies, $120 \mathrm{nmol} \mathrm{MB}$ was injected systemically. Mice were administered blank PBS for control images $(n=3$ mice 

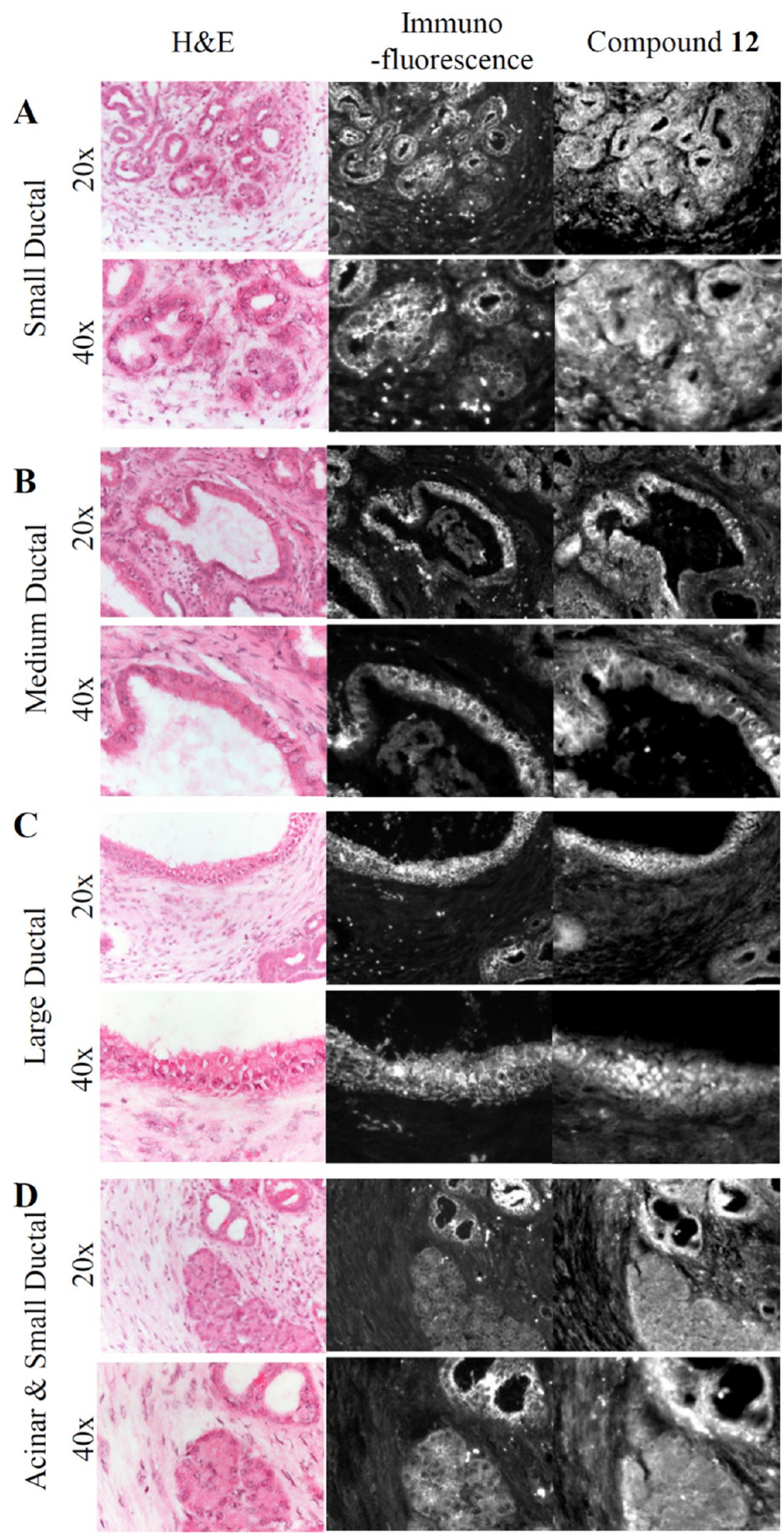

Figure 7. Ex vivo pathology of resected PDAC tissue. Microscopy images of H\&E, pan-cytokeratin, and compound 12 stained slides showing representative (A) small, (B) medium, and (C) large-duct-type adenocarcinoma tissue as well as (D) acinar cells resected from PDAC-bearing mice injected with 12. Pan-cytokeratin antibody staining highlights PDAC cells. Comparison of the fluorescence images obtained with 12 to those obtained with the antibody confirms their similar PDAC-staining patterns. 
per group, 5 groups). For PDAC tumor mice model testing 100 nmol of compound $\mathbf{1 2}$ was injected systemically ( $n=5$ mice).

In Vivo Biodistribution Imaging. The biodistribution of compounds 2, 12, and 13 was assessed using the intraoperative fluorescence imaging system to collect images of the peritoneal cavity. The peritoneal cavity was exposed, and images were collected so that the bladder, adipose tissue, intestine, kidney, liver, muscle, pancreas, spleen, and stomach were visible within the field of view. For initial biodistribution studies, images were collected immediately after injection and at 5, 15, 30, 60, 120, and 240 min following injection. For MB injected mice, images were collected for the same time course, but only up to $60 \mathrm{~min}$ due to the rapid clearance of MB. For PDAC tumor-bearing mice, images were collected immediately after injection and at $5,15,30,60$, and $90 \mathrm{~min}$ following injection. Vehicle-injected control animals were imaged for the same time course as the fluorophore-injected animals for initial testing or immediately following injection only for studies involving $\mathrm{MB}$ or PDAC tumor-bearing mice to assess tissue autofluorescence for comparison to injected animals. Fluorophore biodistribution kinetics were measured using region-of-interest analysis on images collected of the peritoneal cavity. Mean fluorescence intensities in each organ or tissue type were measured from images collected at each time point. All intensities were normalized to the muscle intensity at that time point by dividing by the measured muscle intensity. Using the normalized fluorescence intensities for each organ or tissue type, mean intensities were calculated for each group. Upon completion of initial biodistribution studies, animals were euthanized and their organs were resected. Macroscopic images of the resected organs were collected using the intraoperative fluorescence imaging system, and the mean fluorescence intensity of each resected organ was measured using regionof-interest analysis. Fluorescence intensities were normalized to the muscle intensity in the same manner as in vivo measurements. Mean intensities were calculated for each group using the normalized values. For biodistribution studies in PDAC tumor-bearing mice, only the pancreas was resected and imaged following euthanasia.

Ex Vivo Fluorescence Microscopy, Pathology, and Immunofluorescence Staining. The resected pancreas tissue from compound $\mathbf{1 2}$ in vivo biodistribution studies with PDAC tumor-bearing mice was fixed with $2 \%$ PFA for $12 \mathrm{~h}$, flash frozen in optimal cutting temperature (OCT) compound with liquid nitrogen, and stored at $-80{ }^{\circ} \mathrm{C}$. Cryosections were cut at $10 \mathrm{~m}$ onto Superfrost Plus slides (Fisherbrand, Fisher Scientific). Slides were mounted with Fluoromount-G (Southern Biotech, Birmingham, AL) and coverslipped. Serial sections were obtained for cytokeratin immunofluorescence microscopy, enabling imaging of compound $\mathbf{1 2}$ and immunofluorescence labeling with $0.01 \mathrm{mg} / \mathrm{mL}$ of directly labeled anti-pancytokeratin conjugated to AlexaFluor 488 (eBioscience, San Diego, CA). Briefly, slides were rinsed with PBS for 2 min to remove residual OCT. Then, slides were fixed by immersion in 2\% PFA for $15 \mathrm{~min}$ and washed with PBS for 5 min three times. Primary antibody was incubated on the slides for $1 \mathrm{~h}$ at $\mathrm{rt}$. Following incubation, slides were washed with PBS three times for $5 \mathrm{~min}$ each, then postfixed with PFA for $15 \mathrm{~min}$, and washed with PBS once for $5 \mathrm{~min}$ before mounting with FluoromountG. For cytokeratin immunofluorescence controls, serial sections were stained using the above immunofluorescence procedure but without antibody present in the staining solution that was incubated on the slides. For H\&E pathological analysis, slides previously stained for cytokeratin expression were unmounted and rinsed with PBS to remove residual mournting media before $H \& E$ staining. Images were acquired on an Axio Observer inverted fluorescence microscope (Zeiss, Thornwood, $\mathrm{NY}$ ) at 10,20 , or $40 \times$ magnification. A PhotoFluor II was used unfiltered for $\mathrm{H} \& \mathrm{E}$ color images and filtered using a $545 \pm 12.5$ or $470 \pm 20 \mathrm{~nm}$ bandpass excitation filter for compound 12 or Atto 488 excitation, respectively. Color images were collected using an Axiocam 105 camera (Zeiss) and fluorescence images were collected using an Axiocam 506 camera (Zeiss), where a $605 \pm 35$ or $525 \pm 25 \mathrm{~nm}$ bandpass emission filter was used for compound 12 or Atto 488 fluorescence image collection, respectively.

\section{ASSOCIATED CONTENT}

\section{Supporting Information}

The Supporting Information is available free of charge on the ACS Publications website at DOI: 10.1021/acsomega.6b00403.

Methods, characterization data, and optical properties of new compounds, computer-assisted molecular calculations, macro- and microscopic imaging studies (PDF).

\section{AUTHOR INFORMATION}

\section{Corresponding Author}

*E-mail: strongin@pdx.edu.

ORCID

Lei Wang: 0000-0002-0664-2704

Robert M. Strongin: 0000-0003-3777-8492

\section{Author Contributions}

All authors contributed equally.

Notes

The authors declare no competing financial interest.

\section{ACKNOWLEDGMENTS}

This work was supported by grants from the V Foundation for Cancer Research, the Brenden-Colson Center for Pancreatic Care, and the National Institutes of Health (via grant R15EB016870). We thank Dr. Joe Gray for valuable discussion and Dr. Rosalie Sears of OHSU for the genetically engineered KMC mouse models and Capan-1 cells.

\section{REFERENCES}

(1) Siegel, R. L.; Miller, K. D.; Jemal, A. Cancer statistics, 2016. CaCancer J. Clin. 2016, 66, 7-30.

(2) Rahib, L.; Smith, B. D.; Aizenberg, R.; Rosenzweig, A. B.; Fleshman, J. M.; Matrisian, L. M. Projecting cancer incidence and deaths to 2030: The unexpected burden of thyroid, liver, and pancreas cancers in the United States. Cancer Res. 2014, 74, 2913-2921.

(3) Stathis, A.; Moore, M. J. Advanced pancreatic carcinoma: current treatment and future challenges. Nat. Rev. Clin. Oncol. 2010, 7, 163172.

(4) Li, D.; Xie, K.; Wolff, R.; Abbruzzese, J. L. Pancreatic cancer. Lancet 2004, 363, 1049-1057.

(5) Michalski, C. W.; Weitz, J.; Buchler, M. W. Surgery Insight: surgical management of pancreatic cancer. Nat. Clin. Pract. Oncol. 2007, 4, 526-535.

(6) Verbeke, C. S. Resection margins and R1 rates in pancreatic cancer - are we there yet? Histopathology 2008, 52, 787-796.

(7) Provenzano, P. P.; Cuevas, C.; Chang, A. E.; Goel, V. K.; Von Hoff, D. D.; Hingorani, S. R. Enzymatic targeting of the stroma ablates physical barriers to treatment of pancreatic ductal adenocarcinoma. Cancer Cell 2012, 21, 418-429. 
(8) Choi, H. S.; Gibbs, S. L.; Lee, J. H.; Kim, S. H.; Ashitate, Y.; Liu, F.; Hyun, H.; Park, G.; Xie, Y.; Bae, S.; Henary, M.; Frangioni, J. V. Targeted zwitterionic near-infrared fluorophores for improved optical imaging. Nat. Biotechnol. 2013, 31, 148-153.

(9) Sibrian-Vázquez, M.; Escobedo, J. O.; Lowry, M.; Fronczek, F. R.; Strongin, R. M. Field effects induce bathochromic shifts in xanthene dyes. J. Am. Chem. Soc. 2012, 134, 10502-10508.

(10) Sibrian-Vázquez, M.; Escobedo, J. O.; Lowry, M.; Strongin, R. M. Progress toward red and near-infrared (NIR) emitting saccharide sensors. Pure Appl. Chem. 2012, 84, 2443-2456.

(11) Yang, Y.; Lowry, M.; Schowalter, C. M.; Fakayode, S. O.; Escobedo, J. O.; Xu, X.; Zhang, H.; Jensen, T. J.; Fronczek, F. R.; Warner, I. M.; Strongin, R. M. An organic white light-emitting fluorophore. J. Am. Chem. Soc. 2006, 128, 14081-14092.

(12) Yang, Y.; Lowry, M.; Xu, X.; Escobedo, J. O.; Sibrian-Vázquez, M.; Wong, L.; Schowalter, C. M.; Jensen, T. J.; Fronczek, F. R.; Warner, I. M.; Strongin, R. M. Seminaphthofluorones are a family of water-soluble, low molecular weight, NIR-emitting fluorophores. Proc. Natl. Acad. Sci. U.S.A. 2008, 105, 8829-8834.

(13) Owens, E. A.; Hyun, H.; Tawney, J. G.; Choi, H. S.; Henary, M. Correlating molecular character of NIR imaging agents with tissuespecific uptake. J. Med. Chem. 2015, 58, 4348-4356.

(14) Lipinski, C. A.; Lombardo, F.; Dominy, B. W.; Feeney, P. J. Experimental and computational approaches to estimate solubility and permeability in drug discovery and development settings. Adv. Drug Delivery Rev. 2001, 46, 3-26.

(15) Veber, D. F.; Johnson, S. R.; Cheng, H. Y.; Smith, B. R.; Ward, K. W.; Kopple, K. D. Molecular properties that influence the oral bioavailability of drug candidates. J. Med. Chem. 2002, 45, 2615-2623.

(16) Millard, M.; Gallagher, J. D.; Olenyuk, B. Z.; Neamati, N. A selective mitochondrial-targeted chlorambucil with remarkable cytotoxicity in breast and pancreatic cancers. J. Med. Chem. 2013, 56, 9170-9179.

(17) Wada, H.; Hyun, H.; Vargas, C.; Gravier, J.; Park, G.; Gioux, S.; Frangioni, J. V.; Henary, M.; Choi, H. S. Pancreas-targeted NIR fluorophores for dual-channel image-guided abdominal surgery. Theranostics 2015, 5, 1-11.

(18) di Magliano, M. P.; Logsdon, C. D. Roles for KRAS in pancreatic tumor development and progression. Gastroenterology 2013, 144, 1220-1229.

(19) Hingorani, S. R.; Petricoin Iii, E. F.; Maitra, A.; Rajapakse, V.; King, C.; Jacobetz, M. A.; Ross, S.; Conrads, T. P.; Veenstra, T. D.; Hitt, B. A.; Kawaguchi, Y.; Johann, D.; Liotta, L. A.; Crawford, H. C.; Putt, M. E.; Jacks, T.; Wright, C. V. E.; Hruban, R. H.; Lowy, A. M.; Tuveson, D. A. Preinvasive and invasive ductal pancreatic cancer and its early detection in the mouse. Cancer Cell 2003, 4, 437-450.

(20) Bardeesy, N.; DePinho, R. A. Pancreatic cancer biology and genetics. Nat. Rev. Cancer 2002, 2, 897-909.

(21) Liou, G.-Y.; Döppler, H.; Braun, U. B.; Panayiotou, R.; Scotti Buzhardt, M.; Radisky, D. C.; Crawford, H. C.; Fields, A. P.; Murray, N. R.; Wang, Q. J.; Leitges, M.; Storz, P. Protein kinase D1 drives pancreatic acinar cell reprogramming and progression to intraepithelial neoplasia. Nat. Commun. 2015, 6, No. 6200.

(22) Shi, G.; DiRenzo, D.; Qu, C.; Barney, D.; Miley, D.; Konieczny, S. F. Maintenance of acinar cell organization is critical to preventing KRAS-induced acinar-ductal metaplasia. Oncogene 2013, 32, 19501958.

(23) Frisch, M. J.; Trucks, G. W.; Schlegel, H. B.; Scuseria, G. E.; Robb, M. A.; Cheeseman, J. R.; Scalmani, G.; Barone, V.; Mennucci, B.; Petersson, G. A.; Nakatsuji, H.; Caricato, M.; Li, X.; Hratchian, H. P.; Izmaylov, A. F.; Bloino, J.; Zheng, G.; Sonnenberg, J. L.; Hada, M.; Ehara, M.; Toyota, K.; Fukuda, R.; Hasegawa, J.; Ishida, M.; Nakajima, T.; Honda, Y.; Kitao, O.; Nakai, H.; Vreven, T.; Montgomery, J. A., Jr.; Peralta, J. E.; Ogliaro, F.; Bearpark, M.; Heyd, J. J.; Brothers, E.; Kudin, K. N.; Staroverov, V. N.; Kobayashi, R.; Normand, J.; Raghavachari, K.; Rendell, A.; Burant, J. C.; Iyengar, S. S.; Tomasi, J.; Cossi, M.; Rega, N.; Millam, J. M.; Klene, M.; Knox, J. E.; Cross, J. B.; Bakken, V.; Adamo, C.; Jaramillo, J.; Gomperts, R.; Stratmann, R. E.; Yazyev, O.; Austin, A. J.; Cammi, R.; Pomelli, C.; Ochterski, J. W.; Martin, R. L.;
Morokuma, K.; Zakrzewski, V. G.; Voth, G. A.; Salvador, P.; Dannenberg, J. J.; Dapprich, S.; Daniels, A. D.; Farkas, Ö.; Foresman, J. B.; Ortiz, J. V.; Cioslowski, J.; Fox, D. J. Gaussian 09, revision D.01; Gaussian, Inc.: Wallingford, CT, 2009.

(24) Tuveson, D. A.; Hingorani, S. R. Ductal pancreatic cancer in humans and mice. Cold Spring Harbor Symp. Quant. Biol. 2005, 70, $65-72$.

(25) Jackson, E. L.; Willis, N.; Mercer, K.; Bronson, R. T.; Crowley, D.; Montoya, R.; Jacks, T.; Tuveson, D. A. Analysis of lung tumor initiation and progression using conditional expression of oncogenic K-ras. Genes Dev. 2001, 15, 3243-3248.

(26) Kawaguchi, Y.; Cooper, B.; Gannon, M.; Ray, M.; MacDonald, R. J.; Wright, C. V. The role of the transcriptional regulator Ptfla in converting intestinal to pancreatic progenitors. Nat. Genet. 2002, 32, $128-134$.

(27) Wang, X.; Cunningham, M.; Zhang, X.; Tokarz, S.; Laraway, B.; Troxell, M.; Sears, R. C. Phosphorylation regulates c-Myc's oncogenic activity in the mammary gland. Cancer Res. 2011, 71, 925-936. 